\title{
Comemoração do centenário de nascimento do Prof. Pacheco Prates*.
}

\author{
Vicente Ráo \\ Catedrático de Direito Civil na Faculdade \\ de Direito da Universidade de São Paulo.
}

Há cem anos, exatamente a 16 de Junho de 1856, em Sant'Ana do Livramento, na então província de São Pedro do Rio Grande do Sul, nasceu Manuel Pacheco Prates. Não nasceu entre riquezas, nem em berço doirado se creou, que filho de pai alcáide não era, mas de gente honrada e boa que seu brazão armara com a dureza de seu trabalho e a nobreza de suas virtudes. Nos misteres rudes do campo, penando de sol a sol, sua vida se iniciou e por longo tempo decorreu, pois só aos dezoito anos conseguiu aprender as primeiras letras, sem que sua pobreza lhe permitisse, antes dos vinte e quatro anos de idade, prestar os exames de habilitação para a vida universitária, que havia de ser, até a morte, tôda a sua vida.

Feliz e abençoado comêço, do qual soube auferir o sentido profundamente humano e bondoso, que foi o traço dominante de sua personalidade forte, forjada e temperada no fôgo da luta pela vida.

Nêle, a ponto tal os dons do espírito e do afeto se ajuntavam e fundiam que, se da labuta do campo passou para o lavor do intelecto, não cedeu, tão só, à fôrça de sua inteligência, senão, também, aos impulsos de seu coração,

(*) Discurso proferido em sessão solene da Congregação ao comemorar o centenário de nascimento do Prof. Pacheco Prates. 
para fazer úa creatura que viria a ser a santa companheira de seus dias felizes ou infelizes, de suas alegrias e de seus sofrimentos, não a esposa de um campônio, mas a esposa de um bacharel, como êle próprio costumava dizer, quando aos íntimos narrava êste belo episódio de sua vida. Tão belo e, a um tempo só, tão marcante, que aponta a linha mestra de sua inteira existência, qual seja, a unidade indissolúvel e harmoniosa, que ela ostenta, entre os feitos da vida e os fastos da inteligência, entre o moço que trabalhava no campo seguindo a sorte da mais humilde gente e o mestre que nos cenáculos das letras jurídicas pontificava, ensinando ser o direito, antes de tudo, a ciência e a arte do bom e do justo.

Erraria gravemente o biógrafo que tentasse separar êstes aspectos daqueles, ao traçar o perfil de tão emocionante figura.

COM VINTE e seis anos de idade, aqui veio terminar seus preparatórios e matricular-se, a 31 de Março de 1882, no primeiro ano de nossa Faculdade, onde se formou e recebeu grau a 17 de Março de 1886, após, haver cursado apenas o quarto ano na Escola do Recife.

Logo em seguida, voltou ao seu Estado onde exerceu diversas funções públicas. Foì Promotor de Justiça, Juiz Secional Substituto, Diretor Geral da Instruqão Pública, mas só conseguiu realizar sua aspiração suprema, que sua verdadeira vocação representava, ao ser, em 1900, nomeado lente catedrático de Direito Romano na Faculdade de Direito de Porto Alegre, cargo que brilhantemente exerceu durante cerca de onze anos, até ser transferido para esta Faculdade a 19 de Abril de 1911 a titulo de Professor Extraordinário Efetivo, para assumir, afinal, a 16 de Outubro de 1912, a cátedra de Direito Civil, que tanto honrou, ilustrando-a.

Aos setenta e oito anos, completados em fins de 1934, houve de se aposentar. Do ensino do direito fizera um 




Prof. Manuel Pacheco Prates 
apostolado. Do professorado, uma missão espiritual. Gerações várias, em suas límpidas lições se formaram. Em sua bondade sem limites, sempre encontraram achêgo e nela aprenderam a amar e a compreender os homens. E quando, missão cumprida, nos deixou, aos seus volveu e à sua terra, para o repouso final que bem e justamente merecera.

TAL NA VIDA, tal na cátedra êle sempre foi. Simples, singelo, claro, era seu modo de viver. Simples, singelas, claras, clarissimas, haviam de ser, consequentemente, as suas preleções que, de tão cristalinas, logravam apresentar em têrmos a todos acessiveis, as mais árduas questões e soluções jurídicas.

Conta-se que o professor Herculano de Freitas, homem público e mestre de direito, espírito brilhante e frondeur que manejava com igual mestria o bom humor ou o sarcasmo, certa feita lhe disse: "Prates, tua clareza arruina o nosso prestígio. Quando nós explicávamos a teoria da posse e não nos compreendiam, éramos tidos como sábíos. Agora, com as tuas preleções, não há caloiro que não sáiba o que é a posse e se continuares nesse tom, breve aparecerá quem duvide da profundidade de nossa sabença.

DE UMA COLETÂNEA parcial de suas aulas", extrairei alguns tópicos para demonstrar o quanto eram transparentes, diáfanas, as suas lições.

Assim, ao explicar a distinção entre direitos reais e direitos obrigacionais, Prates iniciava sua preleção nestes precisos têrmos:

"os direitos patrimoniais conferem, ao respectivo "titular, poderes de duas ordens: - primeiro, o "titular exerce o seu poder direto sôbre o objeto, "independentemente da intervenção de outrem; "segundo, o titular exerce o seu poder, direta"mente, sôbre pessoa certa e determinada, que se "obrigou a dar, fazer, ou não fazer alguma cousa. 
"No primeiro caso, o direito tem por objeto ime"diato cousa corpórea, da qual o respectivo titular "retira as vantagens contidas no seu direito. No "segundo caso, o direito tem por objeto direto um "ato ou fato de pessoa determinada, que se obriga "para com o titular. Elucidam o assunto dois "exemplos: $\left(1^{\circ}\right)$ - Pedro tem o direito de pro"priedade sôbre uma cousa corpórea.

"Esste direito lhe confere os poderes de usar da "cousa e de retirar-lhe tôdas as vantagens e uti"lidades, que ela é suscetível de fornecer, sem que "seja necessária a intervenção de outra pessoa, "além do titular do direito. (2.0) - Pedro em"presta a Paulo a importância de um conto de "reis. Por fôrça dêste ato, formou-se, a favor de "Pedro, contra Paulo, um vínculo de direito pelo "qual êste se obriga a entregar àquele a impor"tância que lhe fôra, emprestada. Pedro, que"rendo exercer o seu direito, deverá compelir o "devedor a efetuar o pagamento da importância "a que se obrigara. O objeto imediato do direito "de Pedro é o ato que Paulo deve praticar e não "a importância, porque esta só poderá ser rece"bida, mediante o ato de Paulo. Os direitos da "primeira espécie denominam-se direitos reais, "jus in re, porque recaem diretamente sôbre cousa "corpórea. Nos direitos da segunda espécie, "descobre a análise uma natureza pessoal, por"que o seu exercício depende do ato ou fato de "outra pessoa, além do respectivo titular. Como "êstes direitos geram de relações obrigacionais, "denominam-se, mais pròpriamente, direitos obri"gacionais".

Não direi qualquer estudante de direito, - direi, antes, qualquer leigo e até mesmo um simples colegial entenderia essa explicação, que não é tão elementar quanto parece, 
pois contém noção dos direitos reais e dos direitos obrigacionais, com a indicação de seus elementos constitutivos e o modo de seu exercício e de seu desenvolvimento. E depois de haver, assim, enunciado essas noções básicas, o Mestre claro, - e por todos os títulos preclaro —, ia avançando passo a passo, de grau em grau, até penetrar nos aspectos mais áridos e profundos da matéria, mantendo, sempre, a mesma linguagem desanuviada e lúcida, sem que os seus discípulos se dessem conta, sequer, das dificuldades e das sutilezas que dêsse modo êle vinha vencendo e resolvendo, quer tratasse de distinguir os direitos pessoais das obrigações e direitos pessoais outros, ou os direitos obrigacionais dos direitos reais ligados à pessoa de determinado títular, quer cogitasse de qualificar os chamados contratos reais, ou as obrigações que dos direitos reais resultam, ou as diversas espécies de direitos reais, ou o critério, legal ou doutrinário, de sua enumeração e classificação, - enfim, fôssem quais fôssem, por mais intrincadas, as questões que o assunto pudesse envolver.

DE COSTUME, invocava as fontes romanas para indicar a origem dos institutos sôbre os quais dissertasse quando não o fazia para acentuar a evolução de nosso direito, ou demonstrar, pelo contraste, que de ínovação se tratava, senão de princípios ou normas peculiares em nosso sistema jurídico.

Romanista notável e excelente conhecedor dos textos, de sua cultura romanística extraia um manancial de ensinamentos, que sabia transmitir aos seus alunos de maneira como quê imperceptível, tão suaves e correntias eram as suas exposições. E seus alunos como filhos considerava, tratava e recebia, com extrema bondade, mesmo fora das aulas, para lhes ministrar, com a mesma indefectivel simplicidade, lições complementares, ditando-lhes notas e apontamentos, ou oferecendo livros aos que soubesse serem mais pobres, dádiva que efetuava como quem recebe e não como quem faz um favor. 
SEU CORAÇÃO e sua inteligência, amalgamados no calor humano das lutas de sua mocidade, ditaram-lhe as diretrizes de sua concepção do direito, que para êle não era a simples técnica ou mecânica da disciplina social, mas algo mais elevado e superior, fundado na idéia da liberdade e nos demais direitos essenciais das pessoas, inspirado por princípios supremos éticos e sociais, tendendo para o bem de cada um e para o bem de todos, até alcançar os páramos do ideal.

Sua fé no direito, no bom direito, decorria e se ligava à sua Fé em Deus, Fé que lhe iluminou a existência e êle observou, meiga e docemente, no lar, na cátedra, na sociedade, na comunhão de afeto e de espírito dentro da qual vivia e convivia com os seus e com os seus amigos.

Era um direito humano, humanizado e cristão, o direito que êle cultivava e ensinava.

NOSSO COLEGA professor Ernesto Leme, na sentida oração que proferiu, em sessão fúnebre de 25 de Julho de 1938, comemorando e reverenciando o Mestre, que naquele ano falecera, lembrou que Manuel Pacheco Prates, ainda segundo anista de direito, em 1883 , assim escrevia sôbre a Revolução Riograndense:

“O movimento republicano não partiu de um "só individuo, nem de uma classe privilegiada, "nem tampouco foi a atividade riograndense esti"mulada por agentes externos, foi a própria cons"ciência do povo formada por antecedentes his"tóricos que, compreendendo o grande problema "procurou solvê-lo pela ação expontânea de suas "fôrças materiais e inteletuais livremente consor"ciadas. Os revolucionários daquela heróica cru"zada não foram guiados únicamente pela von"tade de um chefe poderoso nem pela ambição "de um grupo, pois que Bento Gonçalves e seus 
"dígnos companheiros foram arremessados à "frente da revolução pela onda dos acontecimen"tos. Mas, a idéia republicana, embora sufoca"da pelas armas bragantinas, não morreu naquela "província".

Palavras eloquentes eram essas, escritas por quem, havia quatro anos apenas, iniciára seus estudos e, vindo do povo, desde então sentia que só ao povo compete escolher o seu destino, porque movimentos revolucionários legítimos não são os provocados pela ambição de um indivíduo ou de uma casta, mas, tão só, aquêles que da consciência da coletividade emanam e que, por tal origem possuirem, dia mais dia menos sempre a vitória conquistam.

A repulsa ao domínio de um só, ou de um grupo, assim formara, em sua alma moça, um conceito ideal da liberdade, a servir de base à organização civil e política e, pois, a todos os direitos.

E tal era, genuinamente, profundamente humana e espiritual, sua concepção da vida coletiva.

CONCEPÇÃO GENUINAMENTE, profundamente humana e espiritual, a sua, que em todos os seus estudos ou ensinamentos jurídicos penetrava e um cunho de verdadeira sabedoria lhes conferia.

Dissertando sôbre a proteção dos direitos, não comprendia, nem excusava o regresso operado em nosso sistema jurídico por fôrça de certa doutrina romanística alienígena, adotada por autores nossos, com fácil entusiasmo e abandono de institutos tradicionais nossos, em virtude dos quais, pela via dos remédios possessórios, todos os direitos pessoais de exercício continuado outrora encontravam proteção imediata, preventiva ou restauradora contra os atos das autoridades ou de particulares, que atentado constituissem.

Por muito que o Supremo Tribunal, sob a influência de juizes do porte de um Pedro Lessa, procurasse obviar 
o mal causado por essa quebra da continuidade histórica de nosso direito, ampliando e desnaturando o instituto do habeas-corpus, os direitos pessoais, na mór parte dos casos, permaneciam ao desamparo, quando ameaçados, turbados, ou violados em seu exercício. Contra êsse estado de coisas, erguia-se, então, a voz do Mestre, mostrando e demonstrando, doutrina e textos à vista, a necessidade de se volver à solução do amparo possessório, que do direito romano nos viera, reforçada pelo direito canônico e pela velha praxe luso-brasileira. A tese sedutora, que Prates sustentava, apoiava-se, ademais, na magna autoridade de Rur e seguida também era por juízes como Edmundo Lins e Bento de Faria, bem assim por juristas como Francisco Morato, Afrânio de Melo Franco, Levi Carneiro e outros mais que, se não lograram impôr totalmente sua doutrina, prepararam, quando menos, o advento de um remédio novo, ou seja, o do mandado de segurança contra os atos atentórios de direitos líquidos e certos praticados pelas autoridades. É para lamentar, contudo, que êsses mesmos direitos líquidos e certos ainda permaneçam desamparados e sem segurança imediata, quando ameaçados, turbados, ou esbulhados por atos de particulares, a não ser que, extranho paradoxo, seu objeto consista em coisa material e corpórea.

A violência, sob qualquer de suas formas, não encontrava acolhida no espírito do professor Pacheco Prates, fôsse qual fôsse o direito atingido, viesse de quem viesse o atentado.

DESSARTE, sua noção de liberdade civil e política do povo e seu conceito da proteção imediata do exercício de todos os direitos formavam, como quê, um corpo só, complementando-se pelo sentido incisivamente social que êle, como poucos, se empenhava em conferir a todos os institutos jurídicos fundamentais.

Dois exemplos bastam para comprovar o meu asserto. 
Da propriedade, o Mestre eminente dizia e a seus discipulos ensinava:

"tendo em vista o estado atual da cultura huma"na, deve entender-se que seus dois caractéres "absoluto e exclusivo existem circunscritos ao "interêsse geral, - à ordem jurídica e moral. "Dentro dêsses limites há de viver o direito de "propriedade.

Sujeitava a propriedade, pois, aos ditames restritivos impostos pela moral e pelo direito, para que o seu exercício se equacionasse com os interêsses da comunidade, assim afirmando, implìcitamente, a natureza e a função social das normas destinadas a disciplinar a comunhão humana, natureza e função hoje apresentadas como conquista dos tempos modernos, quando, na realidade, sintetizando antigos conceitos, o velho DANTE, em seu tratado de Monarchia já ensinava que “jus est realis et personalis hominis ad hominem proportio: quae servata, hominum servat societatem, et corrupta corrumpit"

Por essas e mais relevantes razões outras, o professor Pacheco Prates repelia a qualificação contratual do casamento, preferindo, para definir a natureza do consenso dos cônjuges, socorrer-se do conceito antigo e genérico de convenção, a fim de poder caraterizar, em seguida, com mais largas vistas e à luz de melhores princípios éticos e espirituais, os efeitos humanos, individuais e sociais, dêsse fundamental instituto jurídico. $\mathrm{E}$ assim dizia e ensinava:

"examinando os fundamentos, fins e efeitos do "casamento, verifica-se que esta instituição com"plexa e ampla se não enquadra na restrita no"ção do contrato, tomado êste vocábulo no seu "sentido próprio ou técnico. O contrato produz "quase todos os seus efeitos entre os contraentes "que expressamente se obrigaram e só indireta"mente interessa à sociedade, como tôda relação 
"de direito. O objeto do contrato, quer seja uma "prestação, quer um serviço, tem sempre valor "econômico convertível em pecúnia. $O$ contrato "gera um direito transitório, do qual se não pode "usar sem extinguí-lo, pois, efetuada a prestação, "dissolve-se o vínculo obrigacional estabelecido "e, com êle, o direito creado pelo contrato. $\mathrm{O}$ "casamento, embora fundado no mútuo consenso. "dos cônjuges, produz diretos e importantìssimos "efeitos sôbre a sociedade, quer quanto aos fun"damentos, quer quanto à existência desta. 0 . "objeto do casamento é fundar uma família nova "e a crear a mútua prestação de auxílio e assis"tência. Os deveres e ofícios decorrentes do ca"samento são quase todos de natureza pessoal, "não têm valor econômico e nem podem ser "prestados em pecúnia. O casamento gera um "vínculo permanente, cujos efeitos se produzem "de contínuo e "se repetem por fôrça do único "ato da celebração do casamento, independente"mente de novo acôrdo".

Considerava, assim, o matrimônio como instituto natural e de direito, sujeito à predominante influência de elementos morais e sociais, por se destinar à creação da família, em cujo seio seus membros reciprocamente se devem auxílio e assistência, constituindo um nucleo ligado aos próprios fundamentos da vida individual e coletiva; e dêsse modo pregava o mesmo princípio básico que a consciência dos povos livres havia de consagrar, em São Francisco, nestes precisos têrmos do art. 26 da Declaração Universal dos Direitos do Homem: "é a família o elemento natural da sociedade, com direito a ser protegida por esta e pelo Estado".

Mas, ao enunciar sua definição e qualificação do casamento, conseguia, ao mesmo tempo, para distinguir uma noção de outra, definir e qualificar o contrato de modo 
claro e perfeito, mais que perfeito e claro, lúcido e translúcido, revelando-nos a fôrça imèdiata de seus efeitos entre as partes obrigadas pelo consentimento, a conversibilidade da prestação em dinheiro e a temporariedade da relação contratual, que pelo cumprimento da obrigação se extingue, extinguindo, ao mesmo passo, o direito por ela creado, - tudo isto para, em seguida, estabelecer e determinar a natureza, essencialmente diversa, dos efeitos produzidos pelo matrimônio. Um mundo de conceitos brota dessa breve lição e insensivelmente, sem o menor esfôrço, penetra em nossa mente, graças ao poder maravilhoso que o professor Pacheco Prates possuia de casar a sintese com a clareza.

MUITO HAVERIA, ainda, a destacar -dentro do muito que nos ensinou e do pouco que nos deixou publicado em suas duas monografias, a Teoria Elementar da F'osse e os Estudos de Direito Civil. Porém, mais que bastantes reputo os exemplos citados, - isto é, sua noção da liberdade civil e política do povo, seu conceito da proteção imediata dos direitos contra tôda e qualquer ameaça, ou turbação, ou violação, sua qualificação da natureza moral e social da propriedade, do matrimônio e da família, para a comprovação final daquilo que denominei a linha mestra de sua personalidade: a unidade inseparável, a harmonia, a coerência, que existe, entre a vida de Pacheco Prates e as suas idéias, entre sua formação humana, moral e cristã e sua formação jurídica, entre quem lutou pela vida, sentindo-a nos seus mais duros transes e quem passou a lutár pelo direito, pelo direito feito do homem para o homem e não de doutrinas apriorísticas impostas à pessoa humana, que por doutrinas não foi creada, mas por Deus à sua imagem.

Não admira que o Mestre houvesse lutado pelo direito de coração aberto e mente volvida, sempre para o Alto, porque assim, também, êle lutou pela vida. 
Que homem bom e sábio êle foi! E Mestre notável que, ensinando, fazia seus discípulos comungarem consigo na crença do direito, do são direito, ciência e arte sublime e bela que a fé em Deus conduz e à vida confere harmonia e paz, fazendo-a digna de ser vivida!

NÃO TIVE a ventura de abraçá-lo quando se despediu de nossa Faculdade e de seus colegas de Congregação. Achava-me, então, ausente, exercendo, no Rio de Janeiro, uma função pública e, por isso, nunca mais tornei a vê-lo. Mas êle, que me examinara e arguíra no concurso que prestei para a conquista da cátedra de direito civil, jamais me esqueceu. Por amigos que vinham ou iam ao Sul, muitas vêzes trocamos mensagens de cordialidade e as suas não escondiam a saudade, que êle sentia, da velha Escola de São Paulo, onde se formou e onde voltou para ensinar a mocidade, onde exerceu o magistério do direito com superioridade tanta, quanto de bondade lhe ia n'alma.

Consciência sempre teve da nobreza do ensino das ciências juridicas, principalmente nesta Casa, onde um passado glorioso vive e, apesar de tôdas as vicissitudes, se perpetua sem solução de continuidade. Se nobre já era sua cátedra ao assumí-la, êle, por êle, com o seu apostolado, mais e mais a enobreceu, pois apóstolo êle foi e não qualquer insensível mestre-escola, dentro dos muros franciscanos dêste Templo do Civismo e do Direito, em que a desalmada frieza burocrática teima em ver apenas, uma simples oficina ou fábrica destinada a diplomar bacharéis em regime de máximo de produção e mínimo de custo, sob moldes estatais amanhados e manipulados em repartições públicas.

AO COMEMORAR, dêsse modo, o centenário do nascimento do professor Pacheco Prates, empenhei-me em reproduzir fielmente sua excepcional figura, sem procurar esconder minha emoção e nem ocultar os meus sentimentos, - que razão e coração bem podem viver juntos na alma 
da gente e, na minha, sempre conservo presente a imagem saudosa do Mestre, a par do pressentimento de sua morte que me assaltou na mesma noite em que, na longínqua cidade de Uruguaiana, êle fechava os olhos para sempre, encerrando a vida que bondosamente, sàbiamente e valentemente vivera.

Nesta fase angustiosa de transição para um futuro desconhecido, que tôda a humanidade atravessa, com frequência os valores se subvertem e as mais belas figuras do passado, próximo ou remoto, se relegam ao olvido. Mas, creiam-me, discípulo ou colega não há que, tendo conhecido o professor Pacheco Prates e com êle convivido, seja capaz de esquecê-lo de não lhe venerar a memória, pois, se mestre êle foi insigne, homem, êle foi santo! 